\title{
ОЦЕНКА ГОТОВНОСТИ ПЕРСОНАЛА ПРЕДПРИЯТИЯ К ВНЕДРЕНИЮ ЦИФРОВЫХ ТЕХНОЛОГИЙ
}

\author{
(c) 2021 Гурцкой Лев Дмитриевич \\ соискатель \\ ФГУП «ВНИИ» Центр» Россия, Москва \\ E-mail: agor80@yandex.ru
}

Человеческий капитал оказывает существенное влияние на внедрение цифровых технологий промышленными предприятиями, поэтому предложено выделить стадии готовности предприятий к внедрению цифровых технологий в зависимости от качества человеческого капитала. Количественная оценка готовности персонала к внедрению цифровых технологий может быть произведена на основе оценки стратегического разрыва. Под стратегическим разрывом понимают разрыв между идеальным уровнем компетенций персонала предприятия, необходимого для работы с цифровыми технологиями и элементами цифровизации, и фактическим. Предложена формула для определения стратегического разрыва промышленного предприятия в цифровой экономике.

Ключевые слова: Цифровизация предприятий, цифровая экономика, цифровые технологии, готовность персонала к работе с цифровыми технологиями, инновации.

В условиях формирования цифровой экономики резко возрастает значимость знаний и информации для обеспечения эффективности хозяйственной деятельности инновационно активных высокотехнологичных промышленных предприятий $[4,6]$. Формируются новые требования к персоналу для работы в условиях внедрения цифровых технологий в производство и в процессы управления предприятиями $[1,7,9]$. Благодаря этому человеческий капитал приобретает новые свойства, функции, компетенции и выступает одним из главных факторов, обеспечивающих инновационное развитие предприятий в условиях их цифровой трансформации [10].

Человеческий капитал оказывает существенное влияние на внедрение цифровых технологий промышленных предприятий, поэтому автором предлагается выделить стадии готовности предприятий к внедрению цифровых технологий в зависимости от качества человеческого капитала [3, 11].

Для того, чтобы определить степень готовности персонала (человеческого капитала) предприятий к внедрению цифровых технологий, необходимо рассмотреть возможные стадии совершенствования системы управления человеческим капиталом на предприятии при его цифровой трансформации [2, 5]. Автор полагает, что чем совершеннее система управления человеческим капиталом на предприятии, тем лучше подготовлен персонал предприятия к внедре- нию цифровых технологий.

Развитие системы управления человеческим капиталом на предприятии предполагает 4 стадии (этапа): аналитически-исследовательская стадия, стадия определения приоритетных задач в области управления человеческим капиталом, организационная стадия, стадия адаптации и реализации отдельных мероприятий.

На первой стадии оценивается уровень цифровизации промышленного предприятия и качество человеческого капитала.

Качество человеческого капитала организации определяется качеством трудового потенциала работника, производительностью их труда, компетентностью и сложностью труда работников. В условиях цифровой экономике меняется отношение к качеству человеческого капитала, первостепенное внимание уделяется не дешевизне рабочей силы, а уровню его образования, навыков и компетенций.

На второй стадии оцениваются необходимые для решения ключевые задачи, которые направленны на повышение эффективности управления человеческим капиталом. Для их выявления сначала определяются основные причины, которые препятствуют внедрению цифровых технологий на высокотехнологичных промышленных предприятиях, а затем определяются стратегические наиболее важные направления развития человеческого капитала.

Третья стадия характеризуется проведением 
организационных мероприятий по реорганизации системы управления человеческим капиталом в интересах инновационного развития высокотехнологичных предприятий, работающих в условиях цифровой экономики, повышающих эффективность управления человеческим капиталом предприятия.

На четвертой стадии управления человеческим капиталом предприятия осуществляется поэтапная реализация политики управления человеческим капиталом в целях внедрения цифровых технологий на промышленном предприятии.

Количественная оценка готовности персонала (человеческого капитала) к внедрению цифровых технологий может быть произведена на основе оценки стратегического разрыва [2, 8]. Под стратегическим разрывом будем понимать разрыв между идеальным уровнем компетенций персонала (человеческого капитала) предприятия, необходимого для работы с цифровыми технологиями и элементами цифровизации, и фактическим.

Автором предлагается следующая формула для определения стратегического разрыва промышленного предприятия Ср в цифровой экономике:

$$
\mathrm{C}_{\mathrm{p}}=\sum_{i=1}^{N} K_{i}\left(Y_{i} / Q_{i}\right)
$$

где $\mathrm{i}$ - элемент цифровой экономики, $\mathrm{N}$ - количество таких элементов, $\mathrm{Y}_{\mathrm{i}}$ - фактический уровень компетенций персонала по работе с і-тым элементом цифровой экономики, $\mathrm{Q}_{\mathrm{i}}$ - требуемый уровень компетенций по работе с i-тым элементом цифровой экономики, $\mathrm{K}_{\mathrm{i}}-$ коэффициент значимости і-го элементы цифровой экономики, причем сумма всех коэффициентов значимости должна быть равна 1.

Проведенный анализ показал, что наибольшие стратегические разрывы имеют место в сфере кибербезопасности, использования искус- ственного интеллекта, по технологиям адаптивного производства, цифровым двойникам, в использовании электронных торговых площадок, цифровых платформ, сквозных технологий. Значительная часть стратегических разрывов связана с использованием такого важного для цифровой экономики элемента, как прогнозирование с использованием «больших данных». Также отмечается стратегический разрыв в корпоративной практике работы с талантами в оценке уровня организационных компетенций персонала.

Для оценки уровня организационных компетенций предлагается использовать пофакторную модель, согласно которой компетенции работников (набор пяти факторов) должны оцениваться с использованием набора показателей, имеющих пять степеней (A, B, C, D, Е), характеризующих различия в выполнении работ, представленную на рисунке 1 .

Для каждой степени А, B, C, D, Е отличия показателей выбирается конкретное число баллов из заданных диапазонов:

$$
\begin{aligned}
& \text { A-12-35; } \\
& \text { B-36-59; } \\
& \text { C-60-83; } \\
& \text { D-84-96; } \\
& \text { E-97-103. }
\end{aligned}
$$

Далее усредненное количество баллов рассчитывается путем деления рассчитанной ранее суммы на количество факторов. Оценка компетентности специалиста производится в соответствии с таблицей 1 .

Официальный перечень ключевых компетенций цифровой экономики включает пять пунктов:

1. Коммуникация и кооперация в цифровой среде.

Компетенция предполагает способность человека в цифровой среде использовать различные цифровые средства, позволяющие во взаимодействии с другими людьми достигать поставленных целей.

Таблица 1. Факторные показатели оценки специалистов

\begin{tabular}{|c|c|c|c|c|c|}
\hline \multirow{2}{*}{ Факторы } & \multicolumn{5}{|c|}{ Степени } \\
\cline { 2 - 6 } & $\mathrm{A}$ & $\mathrm{B}$ & $\mathrm{C}$ & $\mathrm{D}$ & $\mathrm{E}$ \\
\hline 1 & 12 & 36 & 60 & 84 & 97 \\
\hline 2 & 18 & 42 & 66 & 87 & 99 \\
\hline 3 & 24 & 48 & 72 & 90 & 102 \\
\hline 4 & 30 & 54 & 78 & 93 & 105 \\
\hline 5 & 35 & 59 & 83 & 96 & 108 \\
\hline
\end{tabular}




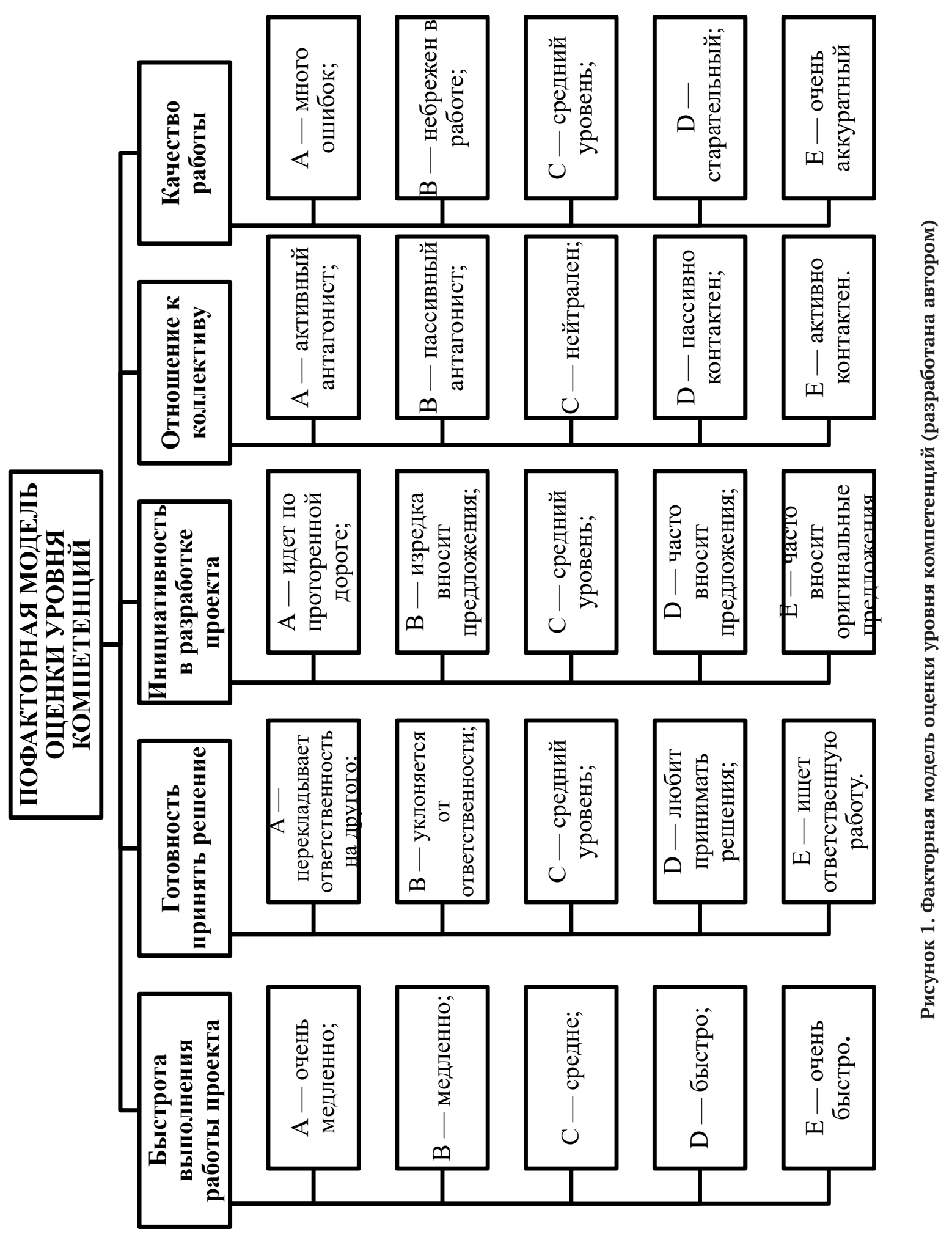


2. Саморазвитие в условиях неопределенности.

Компетенция предполагает способность человека ставить себе образовательные цели под возникающие жизненные задачи, подбирать способы решения и средства развития (в том числе с использованием цифровых средств) других необходимых компетенций.

3. Креативное мышление.

Компетенция предполагает способность человека генерировать новые идеи для решения задач цифровой экономики, абстрагироваться от стандартных моделей: перестраивать сложившиеся способы решения задач, выдвигать альтернативные варианты действий с целью выработки новых оптимальных алгоритмов.

4. Управление информацией и данными.

Компетенция специалиста предполагает его способность находить необходимые ему источники информации или данные, а также дополнительно анализировать и передавать информацию существующими цифровыми средствами с помощью алгоритмов, полученными из различных источников для эффективного использования полученной информации для решения поставленных задач.

5. Критическое мышление в цифровой среде.
Компетенция предполагает способность человека проводить оценку информации, ее достоверность, строить логические умозаключения на основании поступающих информации и данных.

Особое внимание стоит обратить на третий пункт этого перечня (креативное мышление). Ведь не секрет, что цифровая трансформация прежде всего должна происходить в головах владельцев бизнесов, топ-менеджеров, менеджеров среднего звена, а также ключевых специалистов.

Таким образом, в статье показано, что человеческий капитал оказывает существенное влияние на внедрение цифровых технологий промышленных предприятий, предложено выделить стадии готовности предприятий к внедрению цифровых технологий в зависимости от качества человеческого капитала. Количественная оценка готовности персонала к внедрению цифровых технологий может быть произведена на основе оценки стратегического разрыва. Под стратегическим разрывом понимают разрыв между идеальным уровнем компетенций персонала предприятия, необходимого для работы с цифровыми технологиями и элементами цифровизации, и фактическим. Предложена формула для определения стратегического разрыва промышленного предприятия в цифровой экономике.

\section{Библиографический список}

1. Голубев С.С., ГорбуноваВ.В., ЕфремовА.А. Методика отбора приоритетных технологий для развития производственно-технологической базы предприятий ОПК России // Научный вестник обороннопромышленного комплекса России. 2019. № 4. С. 24-29

2. Горохова А.Е. Совершенствование процесса стратегического управления промышленным предприятием // МИР (Модернизация. Инновации. Развитие). 2015. Т. 6. № 2-1 (22). С. 102-107

3. Думанова А.Х., Кумышева 3. Х., Кильчукова А. Л. Роль трудовых ресурсов в переходе к инновационной экономике // Инженерный вестник Дона, 2014, № 4 URL: ivdon.ru/magazine/ archive/N4y2014/2712/

4. Добрынин А.П. Цифровая экономика - различные пути к эффективному применению технологий (ВIM, PLM, CAD, IOT, Smart City, BIGDATA и др.) // International Journal of Open Information Technologies.2016.T.4.

5. Дубов В.С. Показатели оценки развития цифровой экономики // Наука через призму времени. - $2018-$ № 7.

6. Егоров Д. В. Финансовые аспекты цифровой экономики // Банк. дело. - 2017. - № 12.

7. Ефремов А.А. Лизинговые отношения в формировании цепей поставок // Проблемы современной экономики. 2011. № 1 (37). С. 145-148

8. Ефремов А.А. Логистическая стратегия развития сетевых структур лизинга // Известия СанктПетербургского университета экономики и финансов. 2012. № 1 (73). С. 68-74

9. Ефремов А.А., КипперЛ.И. О структуризации логистических цепей и постулатах логистики // Вестник Астраханского государственного технического университета. Серия: Экономика. 2011. № 1. С. 81-85

10. Секерин В.Д., ГороховаА.Е. Интеллектуализация факторов производства как основа инновационного развития промышленных предприятий //Управление инновациями - 2012: Материалы международной научно-практической конференции 19-21 ноября 2012 г. / Под ред. Р.М.Нижегородцева.- М.: ЛЕНАНД, 2012. - 240 c. - С. $127-13$

11. Секерин В.Д. Горохова А.Е. Инновационная среда как фактор эффективности коммерциализации инноваций // Известия Московского государственного технического университета МАМИ. 2014. Т. 5. № 2 (20). С. $39-43$ 